\title{
Characteristics of antibiotics and antibiotic resistance genes in Qingcaosha Reservoir in Yangtze River Delta, China
}

Ting $\mathrm{Xu}^{1,2}$, Wanting Zhao ${ }^{1}$, Xueping Guo ${ }^{1,3^{*}}$, Hongchang Zhang ${ }^{4}$, Shuangqing $\mathrm{Hu}^{4}$, Zhifeng Huang ${ }^{1}$ and Daqiang Yin $^{1,2^{*}}$ (D)

\begin{abstract}
Background: Aquatic ecosystems are considered to be among the most important reservoirs of antibiotic resistance genes (ARGs). Drinking water sources could serve as critical points of ARGs transfer from environment to human. In this study, the distribution of antibiotics and ARGs across Qingcaosha Reservoir located in the Yangtze River Delta during three seasons was investigated to characterize the pollution patterns.

Results: Sulfamethoxazole, sulfamonomethoxine and penicillin G potassium salt were the dominant antibiotics in this reservoir. Sulfonamide resistance genes (sul1 and sul2) were the most prevalent and predominant genes. Higher total relative abundance of the ARGs was detected in the site closest to the inflow than those in other sites. Overall, the concentrations of antibiotics in May were relatively lower than those in November and February. Correlation analysis indicated sul1, ermB and mphA had positive correlation with corresponding antibiotics in February and sul1, sul2, ermB and mphA was also positively correlated to int/1.
\end{abstract}

Conclusion: In conclusion, antibiotics and ARGs were widespread in Qingcaosha Reservoir. Our results indicated that the drinking water reservoir might serve as gene reservoir for antibiotic resistance and mobile gene element int/1 can serve as a medium to contribute to the widespread of various ARGs. As the ARGs abundance was found to be higher in the inflow of the reservoir compared to the outflow, it is considered that reservoir could serve as a functional area contributing to the elimination or dilution of ARGs.

Keywords: Antibiotic resistance genes, Drinking water reservoir, Antibiotic residues

\section{Background}

Nowadays, we are in an era where antibiotics were widely used in clinic, livestock farms, aquaculture and other fields for disease treatment, prophylaxis and growth promoters [1, 2]. Most antibiotics cannot be completely absorbed by humans and animals after intake, of which nearly $25-75 \%$ were discharged via urine and feces [3]. The antibiotic residues could then enter into

\footnotetext{
*Correspondence: xuepingg@tongji.edu.cn; yindq@tongji.edu.cn

${ }^{1}$ Key Laboratory of Yangtze River Water Environment, Ministry

of Education, College of Environmental Science and Engineering, Tongji

University, Shanghai 200092, China

Full list of author information is available at the end of the article
}

the environment and pose a potential risk to ecological microbes and even human health [1]. A growing amount of studies suggested that irrational use and residues of antibiotics possessed long-term selective pressure on microbes and could induce the spread of antibiotic resistant bacteria (ARB) and antibiotic resistance genes (ARGs)[4-7]. Especially for antibiotics such amoxicillin and erythromycin which could be used both in agriculture and clinic, their abuse in animals would cause more a serious situation. Once bacteria have developed resistance to them, it might lead to the failure of infection treatment $[8-10]$.

\section{Springer Open}

(c) The Author(s) 2020. This article is licensed under a Creative Commons Attribution 4.0 International License, which permits use, sharing, adaptation, distribution and reproduction in any medium or format, as long as you give appropriate credit to the original author(s) and the source, provide a link to the Creative Commons licence, and indicate if changes were made. The images or other third party material in this article are included in the article's Creative Commons licence, unless indicated otherwise in a credit line to the material. If material is not included in the article's Creative Commons licence and your intended use is not permitted by statutory regulation or exceeds the permitted use, you will need to obtain permission directly from the copyright holder. To view a copy of this licence, visit http://creativeco mmons.org/licenses/by/4.0/. 
ARG was firstly proposed as an emerging environmental contaminant in 2006 and attracted growing global concern of environments and public health [11]. In recent years, due to the potential risk of ARGs in environment, numerous studies have been performed to assess the prevalence of various ARGs in livestock farms and aquaculture [12], clinical environment [13, 14], wastewater treatment plants [15], reservoirs [16] and even the outflow of drinking water treatment plants [17], surface water all over the world including Germany and Australia [18], Europe [8] and China [19-21]. Therefore, it is obvious that the aquatic environments played critical roles in the regional and global transmission of ARGs and could serve as an important reservoir of them.

Noteworthily, studies related to the survey of ARGs in drinking water source were not frequently reported. Drinking water usually originated from the surface water like rivers and lakes reservoirs which could be easily impacted by anthropogenic activities such as livestock and poultry breeding, agricultural and wastewater discharge [22]. In contract, most of the reservoirs, often acting as main and important drinking water sources relied on an exogenous source, are located in areas with little human activities [23]. Due to the riverine input in source water reservoir, the spread and accumulation of ARGs to increase more serious ecological risk could be caused by some elements, such as some microorganism with antibiotic resistance in raw water [24]. Taken together, it is imperative to investigate the prevalence and distribution of ARGs and assess risk in the headwaters area of the reservoir to guarantee the safety of drinking water supply.

China is one of the largest producers and consumers of antibiotics worldwide, and the usage was estimated to exceed 6 times than the consumption in the UK and most of northern Europe $[25,26]$. In recent years, some studies revealed that the reservoir system could influence the residues and composition of antibiotics exported from the river [27]. Until now, several general studies on antibiotics and ARGs in surface water from the Yangtze estuary were published [20, 28-30]. However, information about the spatial and time variation, and a comprehensive understanding about a specific area is still lacking. Qingcaosha Reservoir is the largest impoundment reservoir of river in China, which covers nearly $66.15 \mathrm{~km}^{2}$ with the effective capacity of 435 million $\mathrm{m}^{3}$. The reservoir freshwater stored and salt avoided officially opened in 2011 with a daily water supply of 7.19 million $\mathrm{m}^{3}$ and the beneficial population of more than 13 million. In this present study, we collected 24 water samples from eight sites of Qingcaosha Reservoir in 3 different months to conduct a comprehensive study. For these aspects showed above, the study aimed to (1) evaluate the frequency and occurrence of 19 antibiotics, 12 ARGs and intI1 in this reservoir; (2) characterize and discuss the spatial and change over time distribution of antibiotics and ARGs; (3) explore the potential linkage among antibiotics, the corresponding ARGs and mobile genetic elements (MGEs). This study will help us better understand the prevalence and fate of ARGs in reservoir systems and provide data support to evaluate the ecological risks of antibiotic resistance in aquatic environment.

\section{Materials and methods}

\section{Study area and sampling campaign}

Qingcaosha Reservoir is located at the mouth of the Yangtze River south branch and north of Changxing Island. Eight sites across the Qingcaosha Reservoir were studied as shown in Fig. 1 for an overall monitor of the reservoir. Water samples were collected about $0.5 \mathrm{~m}$ below the water surface from each sampling site and

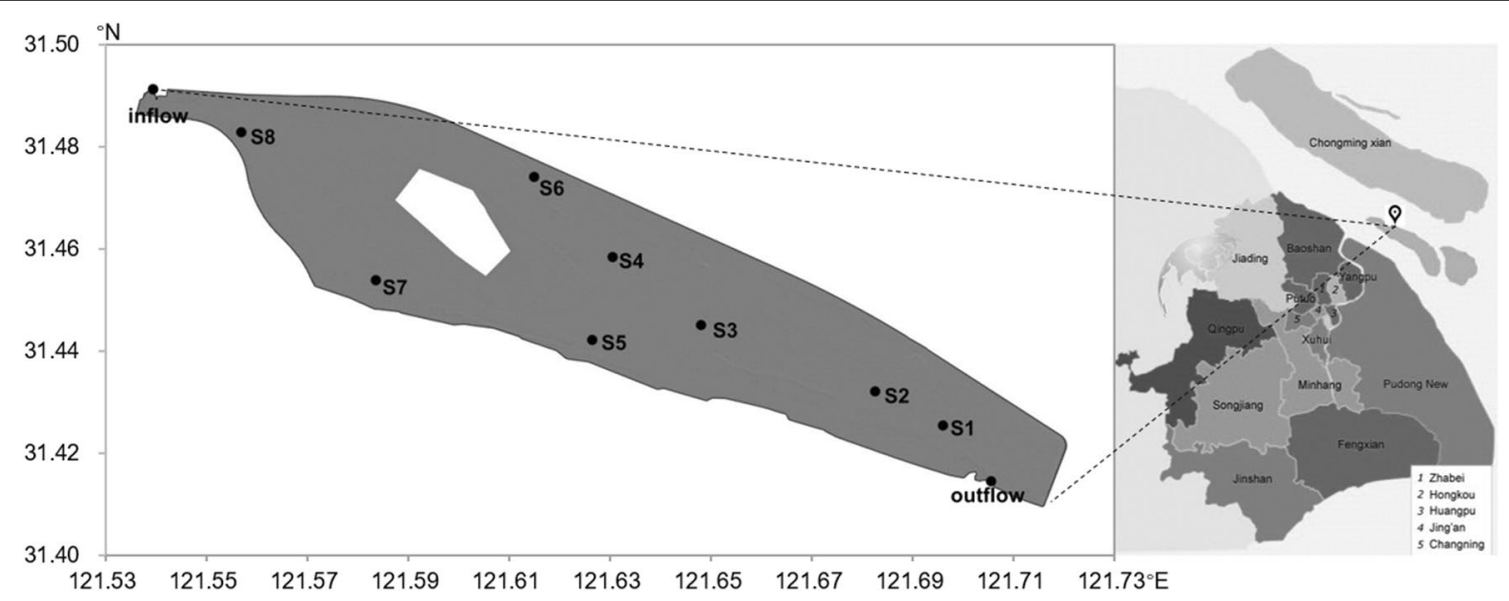

Fig. 1 Map of the Qingcaosha Reservoir and the location of sampling sites 
stored in two sets of different containers. Specifically, $1.5 \mathrm{~L}$ water was stored in sterile polyethylene bottles for DNA extraction and $1 \mathrm{~L}$ water was stored in brown glass bottles for antibiotics analysis. Appropriate amount of hydrochloric acid was added into the glass bottles to a final $\mathrm{pH}$ less than 2 to inhibit microbial activity. Then the water samples were transported to the laboratory on ice and stored at $4{ }^{\circ} \mathrm{C}$ before treatment within $24 \mathrm{~h}$. Sampling campaigns were carried out in November 26th, 2018 with air temperature (AT) ranging from 12 to $17^{\circ} \mathrm{C}$, February 24th, 2019 (AT: $6-12{ }^{\circ} \mathrm{C}$ ) and May 31th, 2019 (AT: $18-25^{\circ} \mathrm{C}$ ), respectively. The precipitation in November 2018 and February 2019 was relatively low, the sampling campaign in May 2019 was characterized by heavy rainfalls.

\section{Determination of antibiotic residues}

Nineteen antibiotics belonging to 6 classes were studied, including seven sulfonamides-sulfamethoxazole (SMX), sulfadiazine (SDZ), sulfachlorpyridazine (SCP), sulfamonomethoxine (SMM), sulfisoxazole (SIZ), sulfamethoxypyrimidine (SMP), and sulfadimidine (SIZ), two tetracyclines-oxycycline (OTC), chlortetracycline (CTC), two $\beta$-lactams-amoxicillin trihydrate (AMC) and penicillin $G$ potassium salt (PenG), three macrolides-azithromycin (AZM), clarithromycin (CLA), and spiramycin (SPM), one aminoglycoside-tilmicosin (TILM) and four quinolones-ciprofloxacin hydrochloride (CIP), fleroxacin (FLX), ofloxacin (OFX), and enrofloxacin (ENR). The above-mentioned antibiotic standards were purchased from Dr. Ehrenstorfer (Germany). A mixture of $\mathrm{SMX}^{-13} \mathrm{C}_{6}$, trimethoprim (TMP)$\mathrm{D}_{3}$, tetracycline (TET) $-\mathrm{D}_{6}$ (the first three standards were purchased from Dr. Ehrenstorfer, Germany), FLX-D ${ }_{5}$, furazolidone (FZD)- $\mathrm{D}_{4}$ (these two were from Witega, Germany), olaquindox (OQX)- $\mathrm{D}_{4}$ and $\mathrm{AMC}^{13} \mathrm{C}_{6}$ (the last two were from Cambridge Isotope Laboratories, UK) served as internal standards for quantification. After activating Oasis HLB column (Waters, USA), loaded the water samples onto the column at a speed of $5 \mathrm{~mL} / \mathrm{min}$. After loading, the column was washed with $6 \mathrm{~mL}$ ultrapure water and $6 \mathrm{~mL} \mathrm{5 \%} \mathrm{methanol-aqueous} \mathrm{solution}$ dried by air for $5 \mathrm{~min}$. Finally, the column was eluted with $10 \mathrm{~mL}$ elution buffer. The eluted solution was blow-dried with nitrogen at $35^{\circ} \mathrm{C}$, and the volume was fixed to $1 \mathrm{~mL}$ with methanol-aqueous solution with a volume concentration of $70 \%$ and the solution was filtered through a $0.22-\mu \mathrm{m}$ PTFE needle filter to a brown injection bottle for testing. All the above treatments were conducted in triplicate, and water samples without adding antibiotics were set as blank.

Antibiotics were quantified by liquid chromatographytriple quadrupole mass spectrometer (Waters, USA).
The mobile phase consisted of (A) acetonitrile and (B) ultra-pure water with $0.1 \%(\mathrm{v} / \mathrm{v})$ formic acid; gradient elution program operated as follows: $0-2.2 \mathrm{~min}, 16 \% \mathrm{~A}$; 2.2-2.5 min, $16-95 \%$ A; 2.5-5.5 min, 95\% A; 5.5-6.0 min, 95-16\% A; 6.0-10.0 min; 16\% A. Chromatographic separation of the analyses was conducted with $\mathrm{BEH} \mathrm{C18} \mathrm{col-}$ umn $(2.1 \times 100 \mathrm{~mm}, 1.7 \mu \mathrm{m}$, Waters, USA $)$ maintained at $35^{\circ} \mathrm{C}$. Mass spectrometric analyses were performed in a triple quadrupole mass spectrometer equipped with an electrospray ionization (ESI) source that operated in the positive ionization mode.

Mixed standard working fluids with antibiotic concentrations ranging from 1.37 to $500.00 \mu \mathrm{g} / \mathrm{L}$ were configured for detection and analysis. The standard curves were obtained with a correlation coefficient greater than 0.993 , and the detection limit was within $0.003-1.230 \mathrm{ng} / \mathrm{L}$.

In the standard recovery experiment, the standard addition level of samples was $100 \mathrm{ng} / \mathrm{L}$ and $200 \mathrm{ng} / \mathrm{L}$ and the recovery rate ranges from 69.4 to $118.5 \%$. The relative standard deviation is less than $10 \%$.

\section{DNA extraction}

The water samples $(500 \mathrm{~mL}$ each) were filtered through $0.22 \mu \mathrm{m}$ polytetrafluoroethylene membrane filters (Millipore, USA) to capture bacteria. The collected membrane filters were stored at $-20{ }^{\circ} \mathrm{C}$ before subsequent DNA extraction. Total DNA was extracted directly from the membranes by using DNeasy PowerSoil Kit (Qiagen, Germany) according to the manufactures' instructions with a final elution volume of $100 \mu \mathrm{L}$. DNA concentrations were determined using $\mathrm{Qubit}^{\mathrm{TM}} 4$ Fluorometer with Qubit $^{\mathrm{TM}}$ dsDNA HS Assay Kit (Invitrogen, USA). All extracted DNA samples were stored at $-40{ }^{\circ} \mathrm{C}$ prior to analysis.

\section{Quantification of ARGs}

The presence of 12 ARGs conferring resistance to the six antibiotic classes and class I integrase gene (intI1) we monitored as well as 16S rRNA gene were investigated. The ARGs included sulfonamide resistance genes (sul1 and sul2), tetracycline resistance genes (tetC and tet $W$ ), $\beta$-lactam resistance genes ( $\operatorname{mp} \mathrm{C}, O X A-1$, and TEM-1), macrolide resistance genes (ermB and $m p h A)$, aminoglycoside resistance genes (aacC4 and $\operatorname{str} A)$, and quinolone resistance genes (qnrS).

The target genes were quantitatively detected with a 7500 real-time PCR System (Applied Biosystems 7500, Thermo Scientific, USA). The real-time qPCR reaction system $(20 \mu \mathrm{L})$ included $10 \mu \mathrm{L}$ of $1 \times$ SensiMix $^{\text {TM }}$ SYBR $^{\circledR}$ No-Rox Kit (Bioline, USA), $0.5 \mu \mathrm{L}$ each of the forward and reverse primers (Sangon Biotech, China), $1 \mu \mathrm{L}$ of DNA templates, $8 \mu \mathrm{L}$ of the $\mathrm{ddH}_{2} \mathrm{O}$. The PCR program was as follows: initial denaturing for $5 \mathrm{~min}$ at $95{ }^{\circ} \mathrm{C}$, 
followed by 40 cycles including denaturing at $95{ }^{\circ} \mathrm{C}$ for $30 \mathrm{~s}$, annealing at different annealing temperatures (Additional file 1: Table S1) for $1 \mathrm{~min}$, extension for $30 \mathrm{~s}$ at $72{ }^{\circ} \mathrm{C}$. Melting curve analysis $\left(55-95{ }^{\circ} \mathrm{C}\right.$, heating rate: $0.5^{\circ} \mathrm{C} / \mathrm{min}$, hold $30 \mathrm{~s}$ ) was conducted for the validation of qPCR product specificity. To avoid the possible inhibition of PCR reaction, the diluted DNA template was analyzed for each sample. The primer sets used for the PCR amplification of ARGs are shown in Additional file 1: Table S1. Double distilled $\mathrm{H}_{2} \mathrm{O}$ was used as negative control for each qPCR array, and all samples were run in triplication. The standard curves were established followed as our previous study [21].

\section{Statistical analysis}

The data were organized in Microsoft Excel 2019, and diagramming was performed with Originpro 9.1 software and Heml: Heatmap Illustrator. The correlation and statistical differences were analyzed using SPSS 22.0 (IBM, USA), one-way ANOVA following a post hoc Dunnett's test at a $p<0.05$ level of significance.

\section{Results}

\section{Antibiotic concentrations}

Fourteen of the 19 target antibiotics were detected in all samples (Fig. 2), with SIZ, SDD, CIP, OFX and TILM not detected in any samples (Additional file 2: Table S2). Among different classes of antibiotics, sulfonamides showed the highest detection frequencies (61.3\%) and aminoglycosides (not detected) the lowest in all samples. The detection frequencies of tetracyclines, $\beta$-lactams, macrolides and quinolones were 29.2\%, 64.6\%, 45.1\% and $16.7 \%$, respectively. For sulfonamides, SMX and SMM could be found in all samples, and SDZ with a high detection rate of $95.8 \%$. SMP and SCP could be detected more frequently in November and February than in May. Both OTC and CTC had low detection frequencies in February, but very differently, the concentration of CTC (36.32 $\mathrm{ng} / \mathrm{L}$ ) was over 44 times higher than that of OTC $(0.81 \mathrm{ng} / \mathrm{L})$. For $\beta$-lactams, PenG could be detected in all samples while the detection frequency of AMC was only $29.2 \%$. The detection frequencies of macrolides were CLA $(58.3 \%)>$ AZM (54.2\%) > SPM (20.8\%). For quinolones, ENR could be detected in November $(1.94 \mathrm{ng} / \mathrm{L})$ and May (2.22 ng/L) and FLX can be only detected in site S8 in November (4.5 ng/L). AZM and CTC were barely detected in November, but were frequently present in February. Quite the opposite, SPM, ENR and OTC were detected in November and more frequently in February.

The mean concentration of SMX was much higher in November $(25.07 \mathrm{ng} / \mathrm{L})$ than in February (3.07 ng/L) and May (5.79 ng/L), while the average contents of SDZ and SMM were close in all three sampling time. The

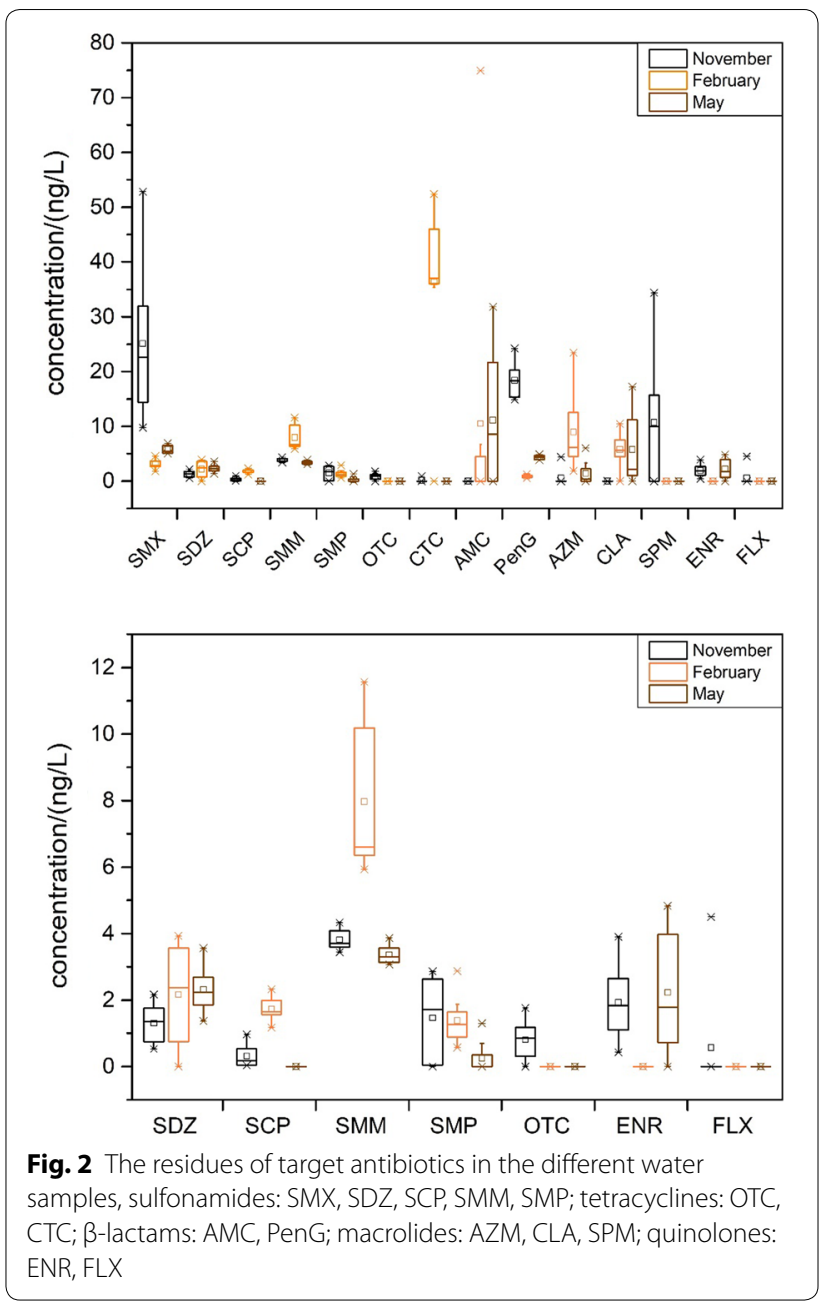

concentration of PenG in November (18.37 ng/L) was significantly higher than those in February $(1.14 \mathrm{ng} / \mathrm{L})$ and May (4.33 ng/L). AZM and CLA were only detected in February (9.39 ng/L, $5.98 \mathrm{ng} / \mathrm{L})$ and May $(1.49 \mathrm{ng} / \mathrm{L}$, $6.51 \mathrm{ng} / \mathrm{L})$. The ENR was always in a low residue ranging from ND to $4.83 \mathrm{ng} / \mathrm{L}$. SMX and PenG were much higher in November than the other two sampling activities. For the detection frequencies and concentrations, SMX, SMM and PenG were dominant antibiotic residues.

\section{Occurrence and distribution of ARGs}

The studied ARGs and intI1 were all detected in Qingcaosha Reservoir. A summary of detection frequencies of 12 ARGs and intI1 in water samples is shown in Table S3. The genes sul1, sul2, tetC, TEM-1, mphA, strA, qnrS and intI1 were detected in all water samples collected in different sampling campaigns. There was little difference among different sampling activities both for sull and sul2. The tet $W$ was detected less frequently in November (12.5\%) and February (12.5\%) than in May (75\%). 
The $\beta$-lactam resistance genes were all detected in February, gene $a m p C$ was less detected in November (75\%) and May (50\%). The gene $O X A-1$ was more frequently detected in February and May (100\%) than November (75\%). The gene $\mathrm{ermB}$ was detected in all of the samples in February and May, while 62.5\% detected in November. In this study, the aacC4 was less detected.

Figure 3 summarizes the abundance of the different subtypes of target genes at all sampling sites in different months of Qingcaosha Reservoir. Generally, the abundance of detected ARGs ranged from $1.21 \times 10^{3}$ to $2.87 \times 10^{8}$ copies/L water in November, from $1.12 \times 10^{3}$ to $3.97 \times 10^{8}$ copies/L water in February and from $2.03 \times 10^{3}$ to $1.01 \times 10^{9}$ copies/L water in May, respectively.

The sul1 and sul2 were predominant in terms of the 12 ARGs, up to $1.01 \times 10^{9}$ copies/L water and $2.87 \times 10^{8}$ copies/L water, respectively. For the two tetracycline resistance genes, tet $C$ was prevalent of the average concentration was $2.36 \times 10^{5}$ copies/L water in November, $5.65 \times 10^{6}$ copies/L water in February and $1.76 \times 10^{6}$ copies/L water in May. In contrast, gene tet $W$ was rarely detected. There was no much difference in the concentration of two macrolide resistance gene $m p h A$ in different water levels caused by rainfall, basically ranged from $2.69 \times 10^{4}$ to $8.78 \times 10^{5}$ copies $/ \mathrm{L}$ water, while $\operatorname{ermB}$ was at a low concentration near the limit of detection. For aminoglycoside resistance genes strA and aacC4, the former was detected ranging from $9.25 \times 10^{4}$ to $7.36 \times 10^{6}$ copies/L water in November, from $7.22 \times 10^{5}$ to $2.33 \times 10^{7}$ copies/L water in February and from $4.99 \times 10^{5}$ to $1.09 \times 10^{7}$ copies/L water in May. In contrast, gene aacC4 ranged from $1.73 \times 10^{3}$ to $6.92 \times 10^{4}$ copies/L water in November and February and not detected in February. The qnrS was 2-3 orders of magnitude higher in February than the other 2 months, which ranged from $2.88 \times 10^{6}$ to $2.95 \times 10^{7}$ copies/L water. As the result showed in this study, the mobile genetic gene intI1 possessed the highest abundance ranging from $6.11 \times 10^{7}$ to $6.56 \times 10^{8}$ copies $/ \mathrm{L}$ water in November, from $3.53 \times 10^{7}$ to $2.56 \times 10^{8}$ copies $/ \mathrm{L}$ water in February and from $5.31 \times 10^{7}$ to $4.55 \times 10^{9}$ copies $/ \mathrm{L}$ water in May.

\section{Variations in the ARGs pattern}

To eliminate the influence of the efficiency of DNA extraction and background interference caused by the microorganisms in aquatic environment, the relative abundance (defined as the absolute number of genes normalized to the absolute number of $16 \mathrm{~S}$ rRNA) was applied to analyze the distribution characteristics of various ARGs among the sampling sites at different times (Fig. 4): sampling temporal (Fig. 4b) and spatial (Fig. 4c)
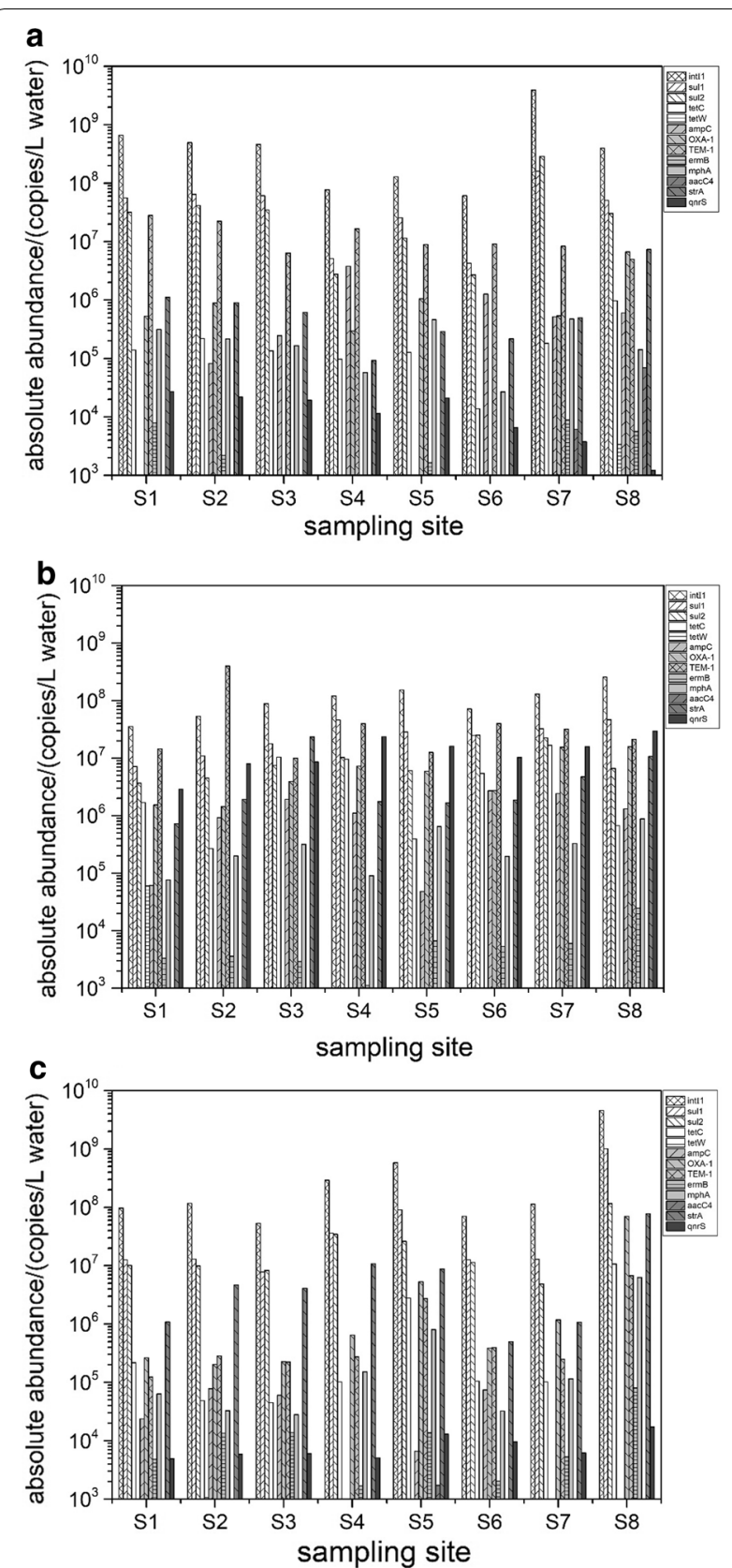

Fig. 3 The absolute abundance of 12 ARGs and int/1 of 8 sampling sites in Qingcaosha Reservoir: a samples collected in November; $\mathbf{b}$ samples collected in February; c samples collected in May

differences in water samples from the Qingcaosha Reservoir.

Figure $4 \mathrm{~b}$ summarizes the total relative abundance of the 12 ARGs and intI1 in November, February, and May from 8 sampling sites in Qingcaosha Reservoir. For ARGs and intI1, the total relative abundance of intII was the highest of $4.21 \times 10^{-1}$, and the sulfonamide resistance genes sul1 and sul 2 were predominant among 12 ARGs 


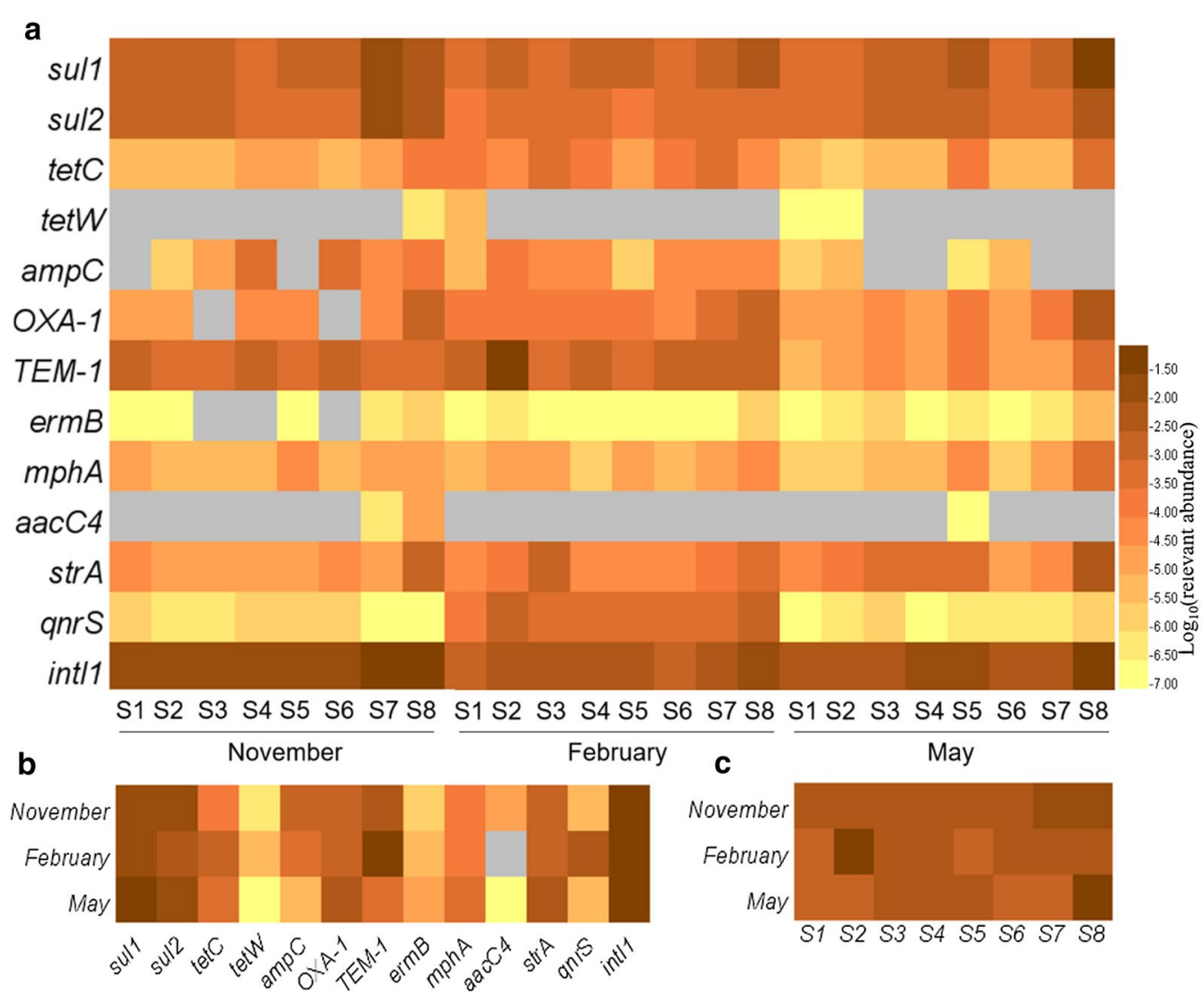

Fig. 4 Heatmap of the relative abundance of target genes: a relative abundance of all target genes; $\mathbf{b}$ variation of summing total target genes in the 8 sampling sites over three sampling campaigns; c distribution of summing total 12 ARGs in the 8 sampling sites. The grey area represented the gene was not detected

range from $3.08 \times 10^{-2}$ to $1.12 \times 10^{-1}$ and $4.12 \times 10^{-3}$ to $2.99 \times 10^{-2}$. Two of the differently encoded genes tetC and tet $W$, the concentration of tetC was much higher than tet $W$. And the same for the aminoglycoside resistance genes, the detection of $s t r A$ was 5 orders of magnitude higher than the aacC4. Among the TEM-1, ampC and $O X A-1$, the total concentration was usually between $10^{-3}$ and $10^{-2}$. Obviously, the overall tendency of abundance of $m p h A$ and ermB was consistent, which was May $>$ February $>$ November. The qnrS was specially caused by the great gaps in February and others.

Obviously, Fig. 4c shows that the total relative abundance of 12 ARGs with site S8 was the relatively high detected $\left(1.88 \times 10^{-2}, \quad 9.63 \times 10^{-3}\right.$ and $\left.8.70 \times 10^{-2}\right)$ among the 8 sampling locations. In particular, there were some high values in the S2 of February $\left(6.6 \times 10^{-2}\right)$ and S7 of November $\left(2.84 \times 10^{-2}\right)$ that were ten times as much as in other sampling campaigns. For ARGs in May, it was apparent that the highest relative abundance of all genes in site S8 and even the sul1, OXA-1 and mphA in S8 were higher 2-3 magnitude orders than other sites.

\section{Correlation analysis between abundance of ARGs}

We carried out a correlation analysis among the absolute concentrations of ARGs, gene intI1 and the antibiotics to which they confer resistance to identify potential links between all variables. A significant positive correlation between the intI1 and ARGs, or several antibiotics and their corresponding ARGs in February was observed (Fig. 5 and Additional file 1: Fig. S1). For instance, there were correlations between the SMX and the sul1 $(r=0.59, p<0.001)$, SMM and the sul1 $(r=0.56$, $p<0.001)$, AZM and the mphA $(r=0.58, p<0.005)$, AZM and the ermB $(r=0.85, p<0.05)$ in February. However, the correlations between antibiotics and ARGs in the other two sampling times or for all sampling activities together were not observed.

\section{Discussion}

Antibiotics and ARGs were commonly found in Qingcaosha Reservoir across different sampling times and sampling sites. As a rather important source of drinking 

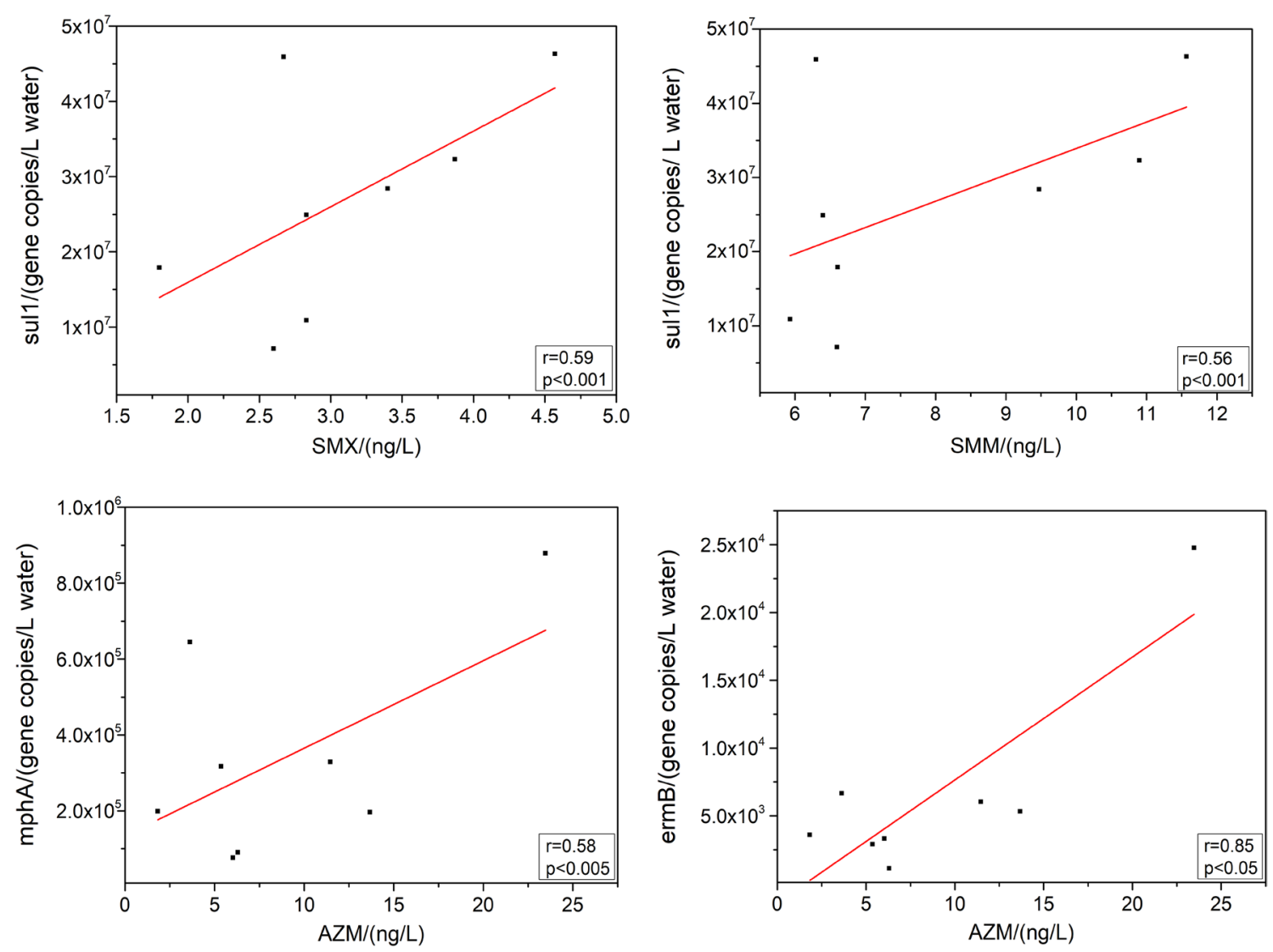

Fig. 5 Correlations between several antibiotics and ARGs in February

water in the Yangtze River Delta, the investigation of Qingcaosha Reservoir could provide us general information of ARGs pollution in this area. The prevalence of ARGs and antibiotics imposed potential risks on humans as the modern drinking water treatment plants were not designed to remove these pollutants. Our result indicated that the reservoir might serve as a gene reservoir for antibiotic resistance, and the presence of ARGs conferring all kinds of antibiotics in the environment was likely related to human activities, such as fecal pollution and antibiotic residues $[31,32]$.

The concentrations of antibiotics in this study were at a medium level compared with previous studies as follows. Not surprisingly, sulfonamides again showed the highest detection frequencies as our previous studies $[17,20]$. Despite the usage of sulfonamides, good compound stability and hydrophilia could support its transportation for a long distance in the aquatic environment [18]. The SMX concentration was comparable to the Guanting Reservoir in north China with the mean concentration of $6.7 \mathrm{ng} \mathrm{L}^{-1}$ [33] and much lower than the Three Gorges Reservoir Area, in which the mean concentration was $13.65 \mu \mathrm{g} \mathrm{L}^{-1}$ [34]. And it was much higher than the Taihu Lake with a mean concentration of $0.355 \mathrm{ng} \mathrm{L}^{-1}$ [35]. The detection frequency and concentration of OTC $\left(25 \%, 0.81 \mathrm{ng} \mathrm{L}^{-1}\right)$ in this study were generally lower than previous reported in Guanting Reservoir $\left(92.9 \%, 15.2 \mathrm{ng} \mathrm{L}^{-1}\right)$ and the lower Yangtze River located in southern Jiangsu Province in dry season $\left(27.2 \%, 18.98 \mathrm{ng} \mathrm{L}^{-1}\right)[33,36]$. For CTC of low detection frequency, but with the mean determined concentration (36.32 $\mathrm{ng} \mathrm{L}^{-1}$ ) was much higher than in Guanting Reservoir (lower than $10 \mathrm{ng} \mathrm{L}^{-1}$ ) and the lower Yangtze River located in southern Jiangsu Province in dry season (lower than $5.86 \mathrm{ng} \mathrm{L}^{-1}$ ) $[33,36]$. The relatively high CTC determined in this study was similar to the reported in the lower Yangtze River located in southern Jiangsu Province in January with less rainfall maybe due to slow degradation in low temperature and high consumption of CTC [36]. In contrast, the concentration of CLA was slightly different from the Yellow River and the Huai River watersheds (lower than $5 \mathrm{ng} \mathrm{L}^{-1}$ ) [37]. Among quinolones group, concentration of ENR ranged from ND to $4.83 \mathrm{ng} \mathrm{L}^{-1}$, which was much lower than in the Three Gorges Reservoir (19.32 $\mathrm{ng} \mathrm{L}^{-1}$ ) with $100 \%$ detection frequency [38]. 
In previous studies, the sulfonamide, tetracycline, $\beta$-lactam, macrolide, aminoglycoside, quinolone resistance genes, and class I integrase gene intI1 were also observed in various environments, including lakes [17], rivers [39-41], wetlands [42], small-scale poultry production [43], and air [44] in China. In our present study, sulfonamide resistance genes sull and sul 2 were the predominant genes among the detected ARGs. The findings in this study were similar to previous studies in which the sul1 and sul2 were also the most abundant ARGs in wetland in Beijing [39] and the Pearl River [45]. The sul1 gene encodes dihydropteroate synthase that confers resistance to sulfonamides and is generally harbored in class I integrase carrying other resistance genes [3]. The high abundance and detected frequency of sul1 found in this study might result from the association with intI1 and the widespread use of sulfonamides in China [25]. And also, the widespread of sul2 was due to the fact that it usually exists on small non-conjugative or large transmissible multi-resistant plasmids [46, 47]. The abundance of sul1 and sul 2 were usually related to input from WWTPs effluent discharge into freshwater and inputs from urban activities such as agricultural runoff, urban discharges and other human activities in previous studies [48, 49], revealed that the water quality in this reservoir is stable and showed no tendency of deterioration in recent years.

The $\beta$-lactam resistance genes were also commonly found and of relatively high abundance, with the concentrations decreased from TEM-1, OXA-1 and ampC. The $T E M-1$ gene was the most frequently detected among the $\beta$-lactams resistance genes, the levels of TEM-1 were higher than those in three man-made reservoirs in Spain $\left(10^{-4}-10^{-3}\right.$ genes/16S rRNA gene abundance) [50] and Taihu Lake $\left(10^{-4}-10^{-3}\right.$ genes copies/16S rRNA gene copies) [17], but comparable to Ba River [51]. The qnrS gene is related with plasmid-borne fluoroquinolone resistance that has become increasingly prevalent in anthropogenically influenced environments [52]. The abundance of $q n r S$ in February was much higher than other seasons with average relative abundance of $8 \times 10^{-4}$. A possible explanation was the lowest temperature and very little precipitation in this period which affect the microbial community.

As the previous studies revealed, the intI1 is ubiquitous and with great abundance in a large-scale clinical and environmental isolates [53-55]. In this study, the absolute abundance of intI1 was greatly positively correlated to several target genes as showed (Fig. S1), including sul1 $(r=0.92, p<0.05)$, sul2 $(r=0.87$, $p<0.05)$, ermB $(r=0.50, p<0.05)$, mphA $(r=0.69$, $p<0.05)$, indicating that the intI1 is likely to acquire and disseminate these related ARG subtypes as gene cassettes, which are unbalanced in the aquatic environment and maybe ultimately derived from human waste or their domestic livestock. Likewise, in the northern yellow sea and pearl river, the results were consistent with previous studies suggesting that intII can serve as a medium to contribute to the widespread of various ARGs, implying that the ARGs maybe transferred by mobile genetic elements from aquatic system to human is possible [37, 56, 57].

Antibiotics residue and its positive correlation with their corresponding ARG subtypes suggested sublethal concentrations of antibiotics might have a high probability to select for resistance to generate genotypic and phenotypic variability between environment and ecosystems [58]. In the present study, sul1, ermB and mphA had a positive correlation with their antibiotics to suggest that some ARGs and antibiotics in the reservoir had identical sources, which was similar to the study result in the urban river in Beijing [18]. However, there was no significant correlation between other antibiotics and ARGs, suggesting that the antibiotics in this reservoir were mainly imported from the external aquatic environment and low antibiotic residue did not exert strong selective pressures.

Compared to the survey on ARGs in Qingcaosha Reservoir in 2016 [16], there is no remarkable abundance of differences that might suggest a dynamic balance of ARGs in this area. But with more sampling sites in Qingcaosha Reservoir in this study, the results can better reflect about more its spatial distribution of antibiotics and ARGs. For antibiotics and ARGs in this reservoir, the studied antibiotics and ARGs tended to be of higher abundance in the sites closer to the inflow of the Qingcaosha Reservoir than those close to the outflow in most cases. Thus, we considered that reservoir could be served as a functional area contributing to the elimination or dilution of ARGs. To be specific, regarding the antibiotics and ARGs results in a temporal and spatial context, some significant tendencies between the different sites in this reservoir and the different sampling times could be observed. In terms of the different sampling sites, higher total relative abundance of the ARGs was detected in site $\mathrm{S} 8$ than those found in other sites. Several antibiotics (including SMX, SMM, AZM, FLX, ENR and CTC) could be found relative to high concentrations in site S8, while the slight differences among all samples for the rest of detected antibiotics, including SDZ, SCP, SMP and OTC. In contrast, the CLA, SPM, and PenG were of high residues in S5 and S6. For ARGs, it was apparent that the relative abundance was higher in S8 (Fig. 3a, c). From the 
map of Qingcaosha Reservoir as Fig. 1 shows, S8 was the nearest site to the raw water from the Yangtze River, suggesting that the raw water maybe the source of the antibiotic residues. Therefore, the occurrence and distribution characteristics of ARGs may be affected by water velocity, geographical conditions and material exchange.

For the different sampling times, the CTC of tetracyclines and macrolides showed the highest concentration of $36.32 \mathrm{ng} \mathrm{L}^{-1}$ in February maybe attribute to the tetracyclines can be degraded when exposure to sunlight combine with the weather condition (the water temperature in November and May was higher than in February) also can influence the antibiotics $[59,60]$. For the other hand, CTC was the most widely used for humans among TC antibiotics, indicating that the CTC maybe used in quantity in February [33]. Compared to other antibiotics, macrolide consumption is more widespread in households to apply to treat specific diseases such as pneumonia and bronchitis [61] and the AZM can be used to treat respiratory infections that are more likely to outbreak in winter. Overall, the antibiotics detected in May were relatively low than November and February maybe caused by the rainfall. However, this concept is inconsistent with a previous finding that more rainfall could increase the absolute abundance of ARGs and MGEs in the river-reservoir system [62]. This phenomenon may be attributed to the differences in the characteristics of river, temperature and location between the system and this reservoir.

\section{Conclusion}

In the present study, we investigated the occurrence and distribution of 19 antibiotics, 12 ARGs and intI1 in the Qingcaosha Reservoir of Shanghai, China. The SMX, SMM and PenG were dominant antibiotics residues for their detection frequencies and concentration in this reservoir. The sulfonamide resistance genes sul1 and sul 2 were the most prevalent and predominant genes in the reservoir. The higher total relative abundance of the ARGs was detected in site S8 than those found in other sites and the overall trend of antibiotics in May was relatively lower than November and February. Correlation analysis indicated sul1, ermB and $m p h A$ had a positive correlation with their antibiotics and intI1 was also greatly positively correlated to $s u l 1, s u l 2, \operatorname{ermB}$ and $m p h A$. Since the reservoirs are the main source of drinking water whether directly or indirectly input, the ARGs pose a serious ecological and human health risk through the horizontal gene transfer in the environment. Overall, our results showed an important view to better understand the antibiotics and ARGs in this reservoir and to provide some information for the safety of aquatic environment management.

\section{Supplementary information}

Supplementary information accompanies this paper at https://doi. org/10.1186/s12302-020-00357-y.

Additional file 1: Table S1. Primers, product lengths and annealing temperatures of quantitative PCR for target genes. Table S3. Detection frequencies of 13 target ARGs in Qingcaosha Reservoir. Figure S1. Correlations between intl1 and ARGs.

Additional file 2: Table S2. Antibiotic residues in Qingcaosha Reservoir.

\section{Abbreviations}

ARGs: Antibiotics resistance genes; qPCR: Quantitative real-time PCR; SMX: Sulfamethoxazole; SDZ: Sulfadiazine; SCP: Sulfachlorpyridazine; SMM: Sulfamonomethoxine; SIZ: Sulfisoxazole; SMP: Sulfamethoxypyrimidine; SIZ: Sulfadimidine; OTC: Oxycycline; CTC: Chlortetracycline; AMC: Amoxicillin trihydrate; PenG: Penicillin G potassium salt; AZM: Azithromycin; CLA: Clarithromycin; SPM: Spiramycin; TILM: Tilmicosin; CIP: Ciprofloxacin hydrochloride; FLX: Fleroxacin; OFX: Ofloxacin; ENR: Enrofloxacin; TMP: Trimethoprim; TCY: Tetracycline; FZD: Furazolidone; OQX: Olaquindox.

\section{Acknowledgements}

Not applicable.

\section{Authors' contributions}

$T X, W Z$, and $X G$ were involved in the experiments and manuscript writing. $Z H$, WZ, and TX were responsible for the data analysis. ZH, TX, and HZ designed the study. TX, SH and DY contributed to correction of the manuscript. All authors read and approved the final manuscript.

\section{Funding}

This study was funded by the National Natural Science Foundation of China (21906121, 21876135 and 21876136), the Foundation of Key Laboratory of Yangtze River Water Environment (Tongji University), Ministry of Education, China (YRWEF201803), and the International Science and Technology Cooperation Program of China (2016YFE0123700).

\section{Availability of data and materials}

The datasets obtained and analyzed in the current study are available from the corresponding author on reasonable request.

\section{Ethics approval and consent to participate} Not applicable.

\section{Consent for publication}

Not applicable.

\section{Competing interests}

The authors declare that they have no competing interests.

\section{Author details}

${ }^{1}$ Key Laboratory of Yangtze River Water Environment, Ministry of Education, College of Environmental Science and Engineering, Tongji University, Shanghai 200092, China. ${ }^{2}$ Shanghai Institute of Pollution Control and Ecological Security, Shanghai 200092, China. ${ }^{3}$ Post-doctoral Research Station of Civil Engineering, Tongji University, Shanghai 200092, China. ${ }^{4}$ Shanghai Academy of Environmental Sciences, Shanghai 200233, China.

Received: 31 December 2019 Accepted: 11 May 2020

Published online: 24 May 2020

\section{References}

1. Kümmerer K (2011) Antibiotics in the aquatic environment. Wiley, Hoboken

2. Sarmah AK, Meyer MT, Boxall ABA (2006) A global perspective on the use, sales, exposure pathways, occurrence, fate and effects of veterinary antibiotics (VAs) in the environment. Chemosphere 65:0-759 
3. Antunes P, Machado J, Sousa JC, Peixe L (2005) Dissemination of sulfonamide resistance genes (sul1, sul2, and sul3) in Portuguese Salmonella enterica strains and relation with integrons. Antimicrob Agents Ch 49:836-839

4. Topp E, Chapman R, Devers-Lamrani M, Hartmann A, Marti R, MartinLaurent F, Sabourin L, Scott A, Sumarah M (2013) Accelerated biodegradation of veterinary antibiotics in agricultural soil following long-term exposure, and isolation of a sulfamethazine-degrading Microbacterium sp. J Environ Qual 42:173-178

5. Devarajan N, Laffite A, Graham ND, Meijer M, Prabakar K, Mubedi Jl, Elongo V, Mpiana PT, Ibelings BW, Wildi W (2015) Accumulation of clinically relevant antibiotic-resistance genes, bacterial load, and metals in freshwater lake sediments in Central Europe. Environ Sci Technol 49:6528-6537

6. Ngangom BL, Tamunjoh SSA, Boyom FF (2019) Antibiotic residues in food animals: public health concern. Acta Ecologica Sinica 39:411-415

7. Shea KM (2003) Antibiotic resistance: what is the impact of agricultural uses of antibiotics on children's health? Pediatrics 112:253-258

8. Allen HK, Donato J, Wang HH, Cloud-Hansen KA, Davies J, Handelsman $J$ (2010) Call of the wild: antibiotic resistance genes in natural environments. Nat Rev Microbiol 8:251-259

9. Segura PA, François M, Gagnon C, Sauvé S (2009) Review of the occurrence of anti-infectives in contaminated wastewaters and natural and drinking waters. Environ Health Perspect 117:675-684

10. Thiele-Bruhn S (2003) Pharmaceutical antibiotic compounds in soils - a review. J Plant Nutr Soil Sc 166:145-167

11. Amy P, Ruoting P, Heather S, Carlson KH (2006) Antibiotic resistance genes as emerging contaminants: studies in northern Colorado. Environ Sci Technol 40:7445-7450

12. Zhu YG, Johnson TA, Su JQ, Qiao M, Guo GX, Stedtfeld RD, Hashsham SA, Tiedje JM (2013) Diverse and abundant antibiotic resistance genes in Chinese swine farms. PNAS 110:3435-3440

13. Davies J (1994) Inactivation of antibiotics and the dissemination of resistance genes. Science 264:375-382

14. Hu FP, Guo Y, Zhu DM, Wang F, Jiang XF, Xu YC, Zhang XJ, Zhang CX, Ji P, Xie $Y$ (2016) Resistance trends among clinical isolates in China reported from CHINET surveillance of bacterial resistance, 2005-2014. Clin Microbiol Infect 22:S9-S14

15. Rizzo L, Manaia C, Merlin C, Schwartz T, Dagot C, Ploy MC, Michael I, Fatta-Kassinos D (2013) Urban wastewater treatment plants as hotspots for antibiotic resistant bacteria and genes spread into the environment: a review. Sci Total Environ 447:345-360

16. Huang Z, Zhao W, Xu T, Zheng B, Yin D (2019) Occurrence and distribution of antibiotic resistance genes in the water and sediments of Qingcaosha Reservoir, Shanghai, China. Environ Sci Eur 31:1-9

17. Guo X, Li J, Yang F, Yang J, Yin D (2014) Prevalence of sulfonamide and tetracycline resistance genes in drinking water treatment plants in the Yangtze River Delta, China. Sci Total Environ 493:626-631

18. Stoll C, Sidhu JPS, Tiehm A, Toze S (2012) Prevalence of clinically relevant antibiotic resistance genes in surface water samples collected from Germany and Australia. Environ Sci Technol 46:9716-9726

19. Li W, Gao L, Shi Y, Liu J, Cai Y (2015) Occurrence, distribution and risks of antibiotics in urban surface water in Beijing, China. Environ Sci Process Impacts 17:1611-1619

20. Stange C, Yin D, Xu T, Guo X, Schäfer C, Tiehm A (2019) Distribution of clinically relevant antibiotic resistance genes in Lake Tai, China. Sci Total Environ 655:337-346

21. Xu Y, Guo C, Luo Y, Lv J, Zhang Y, Lin H, Wang L, Xu J (2016) Occurrence and distribution of antibiotics, antibiotic resistance genes in the urban rivers in Beijing, China. Environ Pollut 213:833-840

22. Liao K, Bai Y, Huo Y, Jian Z, Hu W, Zhao C, Qu J (2018) Integrating microbial biomass, composition and function to discern the level of anthropogenic activity in a river ecosystem. Environ Int 116:147-155

23. Chen Y, Su JQ, Zhang J, Li P, Chen H, Zhang B, Gin KYH, He YL (2019) Highthroughput profiling of antibiotic resistance gene dynamic in a drinking water river-reservoir system. Water Res 149:179-189

24. Dang B, Mao D, Xu Y, Luo Y (2017) Conjugative multi-resistant plasmids in Haihe River and their impacts on the abundance and spatial distribution of antibiotic resistance genes. Water Res 111:81-91

25. Zhang QQ, Ying GG, Pan CG, Liu YS, Zhao JL (2015) Comprehensive evaluation of antibiotics emission and fate in the river basins of China: source analysis, multimedia modeling, and linkage to bacterial resistance. Environ Sci Technol 49:6772-6782

26. Qiao M, Ying GG, Singer AC, Zhu YG (2018) Review of antibiotic resistance in China and its environment. Environ Int 110:160-172

27. Chen Y, Chen H, Zhang L, Jiang Y, Gin K, He Y (2018) Occurrence, distribution, and risk assessment of antibiotics in a subtropical river-reservoir system. Water 10:104

28. Jiang Y, Xu C, Wu X, Chen Y, Han W, Gin K, He Y (2018) Occurrence, seasonal variation and risk assessment of antibiotics in Qingcaosha reservoir. Water 10:115

29. Xu Z, Jiang Y, Te S, He Y, Gin K (2018) The effects of antibiotics on microbial community composition in an estuary reservoir during spring and summer seasons. Water 10:154

30. Jiang L, Hu X, Xu T, Zhang H, Sheng D, Yin D (2013) Prevalence of antibiotic resistance genes and their relationship with antibiotics in the Huangpu River and the drinking water sources, Shanghai, China. Sci Total Environ 458-460:267-272

31. Karkman A, Pärnänen K, Larsson DJ (2019) Fecal pollution can explain antibiotic resistance gene abundances in anthropogenically impacted environments. Nat Commun 10:80

32. Bengtsson-Palme J (2018) The diversity of uncharacterized antibiotic resistance genes can be predicted from known gene variants-but not always. Microbiome 6:125

33. Zhang P, Zhou H, Li K, Zhao X, Liu Q, Li D, Zhao G (2018) Occurrence of pharmaceuticals and personal care products, and their associated environmental risks in a large shallow lake in north China. Environ Geochem Health 40:1525-1539

34. Hamid N, Junaid M, Pei D-S (2020) Individual and combined mechanistic toxicity of sulfonamides and their implications for ecological risk assessment in the Three Gorges Reservoir Area (TGRA). China. J Hazard Mater 382:121106

35. Xu Z, Tao L, Jun B, Ce W (2018) Spatiotemporal heterogeneity of antibiotic pollution and ecological risk assessment in Taihu Lake Basin, China. Sci Total Environ 643:12-20

36. Wang Z, Chen Q, Zhang J (2019) Characterization and source identification of tetracycline antibiotics in the drinking water sources of the lower Yangtze River. J Environ Manage 244:13-22

37. Sun J, Luo Q, Wang D (2015) Occurrences of pharmaceuticals in drinking water sources of major river watersheds, China. Ecotox Environ Safe 117:132-140

38. Yan M, Xu C, Huang Y (2018) Tetracyclines, sulfonamides and quinolones and their corresponding resistance genes in the Three Gorges Reservoir, China. Sci Total Environ 631:840-848

39. Chen B, Liang X, Huang X, Zhang T, Li X (2013) Differentiating anthropogenic impacts on ARGs in the Pearl River Estuary by using suitable gene indicators. Water Res 47:2811-2820

40. Chen B, Liang X, Nie X, Huang X, Zou S, Li X (2015) The role of class I integrons in the dissemination of sulfonamide resistance genes in the Pearl River and Pearl River Estuary, South China. J Hazard Mater 282:61-67

41. Luo Y, Mao D, Rysz M, Zhou Q, Zhang H, Xu L, Alvarez JJP (2010) Trends in antibiotic resistance genes occurrence in the Haihe River, China. Environ Sci Technol 44:7220-7225

42. Li S, Zhang R, Hu J, Shi W, Kuang Y, Guo X, Sun W (2019) Occurrence and removal of antibiotics and antibiotic resistance genes in natural and constructed riverine wetlands in Beijing, China. Sci Total Environ 664:546-553

43. Guo X, Stedtfeld RD, Hedman H, Eisenberg J, Truebac G, Yin D, Tiedje JM, Zhang L (2018) Antibiotic resistome associated with small-scale poultry production in rural ecuador. Environ Sci Technol 46:W282-W288

44. Li J, Cao J, Zhu YG, Chen QL, Shen F, Wu Y, Xu S, Fan H, Da G, Huang RJ, Wang J, de Jesus AL, Morawska L, Chan CK, Peccia J, Yao M (2018) Global survey of antibiotic resistance genes in air. Environ Sci Technol 52:10975-10984

45. Li A, Chen L, Zhang Y, Tao Y, Xie H, Li S, Sun W, Pan J, He Z, Mai C (2018) Occurrence and distribution of antibiotic resistance genes in the sediments of drinking water sources, urban rivers, and coastal areas in Zhuhai, China. Environ Sci Pollut Res 25:26209-26217

46. Enne VI, Livermore DM, Stephens P, Hall LM (2001) Persistence of sulphonamide resistance in Escherichia coli in the UK despite national prescribing restriction. Lancet 357:1325-1328

47. Sköld O (2000) Sulfonamide resistance: mechanisms and trends. Drug Resist Updates 3:155-160 
48. Nnadozie CF, Odume ON (2019) Freshwater environments as reservoirs of antibiotic resistant bacteria and their role in the dissemination of antibiotic resistance genes. Environ Pollut. 254:113067

49. Devarajan N, Laffite A, Mulaji CK, Otamonga JP, Mpiana PT, Mubedi Jl, Prabakar K, Ibelings BW, Poté J (2016) Occurrence of antibiotic resistance genes and bacterial markers in a tropical river receiving hospital and urban wastewaters. PLoS ONE 11:e0149211

50. Huerta B, Marti E, Gros M, López P, Pompêo M, Armengol J, Barceló D, Balcázar JL, Rodríguez-Mozaz S, Marcé R (2013) Exploring the links between antibiotic occurrence, antibiotic resistance, and bacterial communities in water supply reservoirs. Sci Total Environ 456:161-170

51. Jia J, Guan Y, Cheng M, Chen H, He J, Wang S, Wang Z (2018) Occurrence and distribution of antibiotics and antibiotic resistance genes in Ba River, China. Sci Total Environ 642:1136-1144

52. Marti E, Variatza E, Balcázar JL (2014) Bacteriophages as a reservoir of extended-spectrum $\beta$-lactamase and fluoroquinolone resistance genes in the environment. Clin Microbiol Infect 20:0456-0459

53. Labbate M, Case RJ, Stokes HW (2009) The integron/gene cassette system: an active player in bacterial adaptation. Horiz Gene Transf. 532:103-125

54. Shah SQA, Colquhoun DJ, Nikuli HL, Sørum H (2012) Prevalence of antibiotic resistance genes in the bacterial flora of integrated fish farming environments of Pakistan and Tanzania. Environ Sci Technol 46:8672-8679

55. Yan H, Li L, Zong M, Alam MJ, Shinoda S, Shi L (2010) Occurrence and characteristics of class 1 and 2 Integrons in clinical bacterial isolates from patients in South China. J Health Sci 56:442-450
56. Na G, Zhang W, Zhou S, Gao H, Lu Z, Wu X, Li R, Qiu L, Cai Y, Yao Z (2014) Sulfonamide antibiotics in the Northern Yellow Sea are related to resistant bacteria: implications for antibiotic resistance genes. Mar Pollut Bull 84:70-75

57. Martínez José L, Coque TM, Baquero F (2014) What is a resistance gene? Ranking risk in resistomes[J]. Nat Rev Microbiol 13:116-123

58. Andersson DI, Hughes D (2014) Microbiological effects of sublethal levels of antibiotics. Nat Rev Microbiol 12:465-478

59. Huang C-H, Renew JE, Smeby KL, Pinkston K, Sedlak DL (2011) Assessment of potential antibiotic contaminants in water and preliminary occurrence analysis. J Contemp Water Res Educ 120:4

60. Peak N, Knapp CW, Yang RK, Hanfelt MM, Smith MS, Aga DS, Graham DW (2007) Abundance of six tetracycline resistance genes in wastewater lagoons at cattle feedlots with different antibiotic use strategies. Environ Microbiol 9:143-151

61. Kümmerer K, Henninger A (2003) Promoting resistance by the emission of antibiotics from hospitals and households into effluent. Clin Microbiol Infect. 9:1203-1214

62. Cesare AD, Eckert EM, Corno G (2017) Rainfall increases the abundance of antibiotic resistance genes within a riverine microbial community. Environ Pollut. 226:473-478

\section{Publisher's Note}

Springer Nature remains neutral with regard to jurisdictional claims in published maps and institutional affiliations.

\section{Submit your manuscript to a SpringerOpen ${ }^{\circ}$ journal and benefit from:}

- Convenient online submission

- Rigorous peer review

- Open access: articles freely available online

- High visibility within the field

Retaining the copyright to your article

Submit your next manuscript at $\boldsymbol{\nabla}$ springeropen.com 